\title{
ESTUDO DA UTILIZAÇÃO DA LAMA VERMELHA ATIVADA QUIMICAMENTE E TERMICAMENTE VISANDO A DESACIDIFICAÇÃO DE BIOCOMBUSTÍVEL*
}

Fernanda Borba Simões ${ }^{1}$

Lucas Athaydes Ferreira da Silva² Karllen Camila Cruz de Cristo ${ }^{1}$

Torben Ulisses da Silva Carvalho ${ }^{2}$ Silvio Alex Pereira da Mota ${ }^{3}$

\section{Resumo}

$\mathrm{Na}$ produção de biocombustíveis a partir de óleos vegetais produzidos via craqueamento térmico-catalítico, é realizada a desacidificação do produto final para sua viabilidade, podendo ser efetuada pela adsorção. Os adsorventes são diversificados e vão desde zeólitas até o uso de resíduos industriais. Este trabalho buscou testar a lama vermelha previamente ativada quimicamente e termicamente como adsorvente de ácidos graxos livres presentes no gasóleo leve produzido a partir do craqueamento do óleo de palma com índice de acidez inicial de 55,1257 mg de $\mathrm{KOH} / \mathrm{g}$. A lama vermelha foi utilizada em cinco condições: seca sem tratamento, ativada quimicamente (pré-tratada a $400^{\circ} \mathrm{C} / 2 \mathrm{~h}$ ) por solução de $\mathrm{HCl}$ a $37 \%$, de $\mathrm{H}_{2} \mathrm{O}_{2}$ a $4 \%$, de $\mathrm{HCl}$ a $1,5 \mathrm{M}$ e de $\mathrm{KOH}$ a $1,5 \mathrm{M}$. Na cinética de adsorção, a lama vermelha ativada por solução de $\mathrm{HCl}$ a $1,5 \mathrm{M}$ mostrou-se mais eficiente que os demais adsorventes, pois reduziu o índice de acidez do biocombustível de 10,7574 mg de $\mathrm{KOH} / \mathrm{g}$ para $9,1752 \mathrm{mg}$ de $\mathrm{KOH} / \mathrm{g}$ no tempo de 50 minutos. Quanto à eficiência dos adsorventes restantes, no que tange a desacidificação, apenas a lama vermelha seca e a ativada quimicamente por $\mathrm{KOH}$ a 1,5 M apresentaram remoção dos ácidos graxos livres perceptíveis.

Palavras-chave: Lama vermelha; Adsorção; Ativação química; Ativação térmica.

\section{STUDY OF UTILIZATION OF RED MUD CHEMICALLY AND THERMAL ACTIVATE AIMING THE BIOFUEL DESACIDIFICATION}

\section{Abstract}

In the production of biodiesel from vegetable oil produced via thermal, catalytic cracking, the desacidification of the final product is carried out for viability and can be effected by adsorption. The adsorbents are diverse and range from zeolites to the use of industrial waste. This study aimed to test the red mud, previously activated chemically and thermally, as an adsorbent of free fatty acids present in the light gas oil, produced from the cracking of palm oil with an initial acid value of $55.1257 \mathrm{mg}$ $\mathrm{KOH} / \mathrm{g}$. Red mud was used in five conditions: dry untreated, chemically activated (pretreated at $400^{\circ} \mathrm{C} / 2 \mathrm{~h}$ ) by $\mathrm{HCl} 37 \%$ solution, by $\mathrm{H}_{2} \mathrm{O}_{2} 4 \%$ solution, by $\mathrm{HCl} 1.5 \mathrm{M}$ solution and by $\mathrm{KOH} 1.5 \mathrm{M}$ solution. The adsorption kinetics, the red mud solution activated by $\mathrm{HCl} 1.5 \mathrm{M}$ was more effective than the other adsorbents, for biofuel reduced the acid value of $10.7574 \mathrm{mg} \mathrm{KOH} / \mathrm{g}$ to $9.1752 \mathrm{mg} \mathrm{KOH} / \mathrm{g}$ at the time of 50 minutes. As for the efficiency of other adsorbents, with respect to desacidification, only the dry red mud and chemically activated by $\mathrm{KOH} 1.5 \mathrm{M}$ showed noticeable removal of free fatty acids.

Keywords: Red mud; Adsorption; Chemical activation; Thermal activation.

1 Graduada em Engenharia de Materiais, Bacharel, Faculdade de Engenharia de Materiais, Universidade Federal do Sul e Sudeste do Pará, Marabá, Pará, Brasil.

2 Graduando em Engenharia de Materiais, Estudante, Faculdade de Engenharia de Materiais, Universidade Federal do Sul e Sudeste do Pará, Marabá, Pará, Brasil.

3 Graduado em Engenharia Química, Doutor, Faculdade de Engenharia de Materiais, Universidade Federal do Sul e Sudeste do Pará, Marabá, Pará, Brasil. 


\section{INTRODUÇÃO}

À medida que as principais fontes de energia como o petróleo, carvão e gás natural estão gradualmente se esgotando, associado à conscientização mundial, fica evidenciada a necessidade de mudanças nos hábitos de consumo da população. Nesse contexto é corroborada a busca e incentivo a pesquisas e desenvolvimento de novos combustíveis obtidos de fontes renováveis, os chamados biocombustíveis.

Os biocombustíveis estão sendo cada vez mais aperfeiçoados para que possam substituir o petróleo e seus derivados. Uma das rotas para obtenção de biocombustíveis a partir de óleos vegetais é o craqueamento térmico-catalítico, que consiste na quebra das moléculas em altas temperaturas, na presença ou não de catalisadores [1]. Porém no produto final do craqueamento geram-se moléculas de elevada acidez exigindo novas reações para especificar o produto. Por este motivo há necessidade da desacidificação dos óleos brutos obtidos até níveis adequados para a produção de biocombustíveis.

Dentre os métodos de desacidificação, pode-se citar a utilização de adsorventes zeólitas, carvão ativado e materiais residuais com potencial de adsorção como a lama vermelha, a qual apresenta ainda uma elevada alcalinidade [2]. A disposição inadequada da lama vermelha pode originar problemas como contaminação da água de superfície e subterrânea por hidróxido de sódio, alumínio ou outro agente químico contido na mesma [3]. Diante disto, a elevada geração de lama vermelha leva as indústrias de produção de alumínio a investirem fortemente em pesquisas de reaproveitamento do resíduo [4]. Nestes termos, muitas pesquisas vêm sendo realizadas visando desenvolver alternativas viáveis industrialmente para uso da lama vermelha [5].

Baseado neste cenário, e objetivando o reaproveitamento da lama vermelha, o presente trabalho estudou a viabilidade da utilização da lama vermelha tratada quimicamente e termicamente, sendo a ativação química realizada com ácido clorídrico, peróxido de hidrogênio e hidróxido de potássio, seguido da etapa de calcinação objetivando-se a obtenção de um material adsorvente economicamente viável com aplicabilidade na desacidificação de biocombustíveis (diesel leve) obtido via rota tecnológica de craqueamento.

\section{MATERIAIS E MÉTODOS}

Para a investigação da viabilidade de material adsorvente, foi utilizada a lama vermelha proveniente do processo Bayer da empresa Hydro Alunorte. $O$ biocombustível utilizado como insumo de ácidos graxos livres foi obtido no Laboratório de Processos de Separações Térmicas e Produção de Biocombustíveis (THERMTEK/FEQ/ITEC/UFPA), segundo o procedimento de produção descrito por Mota [6].

Para realizar o presente estudo as seguintes etapas foram realizadas: secagem, moagem, peneiramento, ativação química (com ácido clorídrico e peróxido de hidrogênio) e térmica, além das análises necessárias para caracterizar o material residual seco e o ativado (TGA, DTA, Espectrômetro de Raios-X, Infravermelho e DRX).

Já o biocombustível utilizado é proveniente do craqueamento do óleo de palma obtido por destilação fracionada em escala de bancada. Nesta destilação as frações foram removidas de acordo com a temperatura, os produtos obtidos foram: biogasolina, bioquerosene, diesel leve e diesel pesado. Sendo o diesel leve o biocombustível a ser 
desacidificado no presente trabalho. Toda a metodologia adotada pode ser visualizada através da Figura 1.

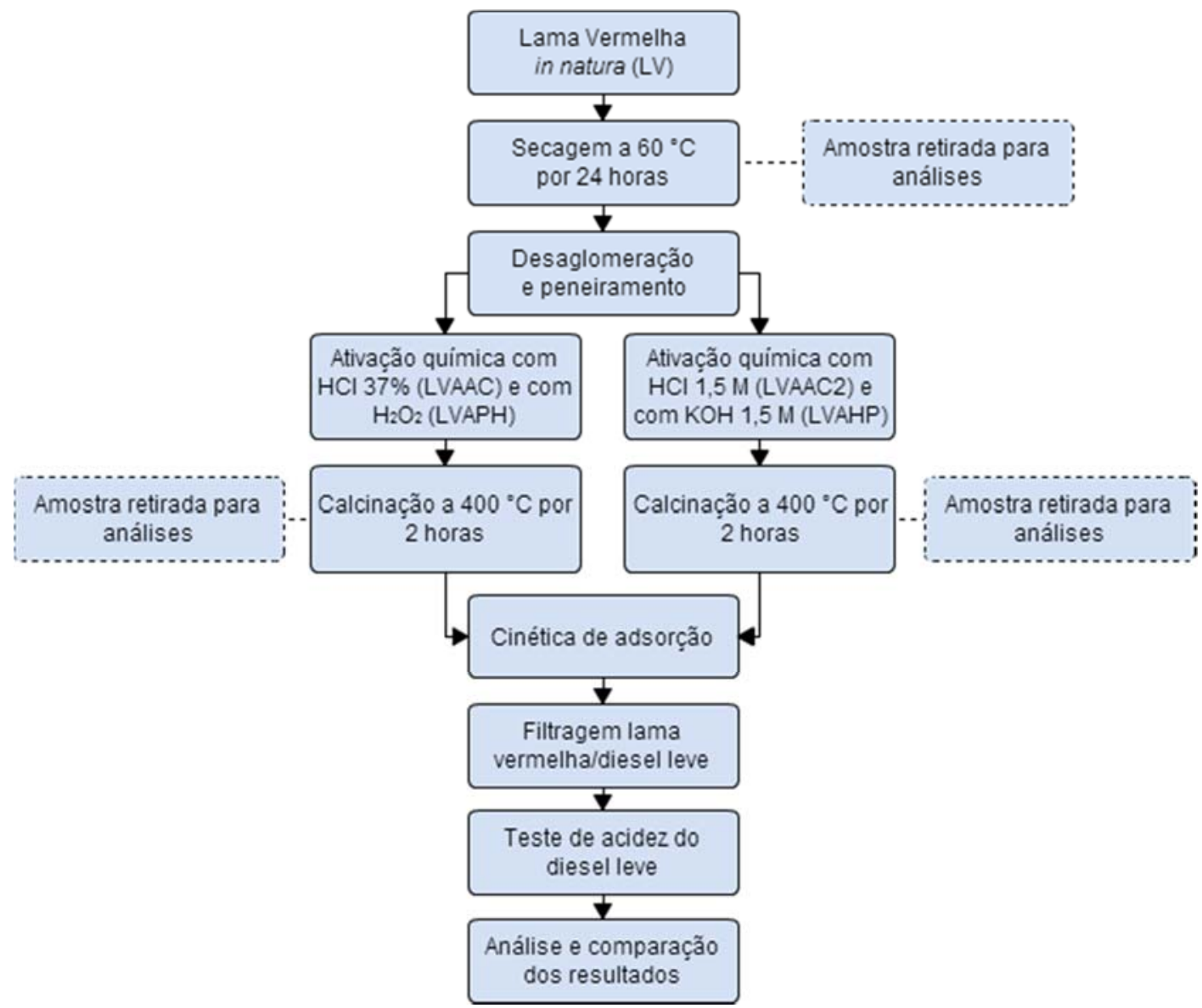

Figura 1. Fluxograma da desacidifcação do diesel leve e dos tratamentos realizados na lama vermelha a fim de melhorar seu desempenho como adsorvente.

\section{RESULTADOS E DISCUSSÃO}

Para o aumento da eficiência dos materiais como adsorvente, ambos foram calcinados a $400^{\circ} \mathrm{C}$, pois Antunes, Conceição e Navarro [7] concluíram em seu estudo, a partir da análise da área superficial especifica obtidas pelo método B.E.T., que o tratamento térmico na lama vermelha contribui com um aumento na área superficial específica, mas a partir de $600^{\circ} \mathrm{C}$ há uma redução da área específica justificada pela formação de mesoporos.

A análise térmica foi realizada na lama vermelha ao final de cada ativação química, e as Figuras 2, 3, 4a, 4b e 4c trazem os resultados obtidos nas amostras de lama nas respectivas condições: seca sem tratamento, ativada quimicamente por solução de $\mathrm{H}_{2} \mathrm{O}_{2}$ a $4 \%$, ativada quimicamente por solução de $\mathrm{HCl}$ a $37 \%$, ativada quimicamente por solução de $\mathrm{KOH}$ a $1,5 \mathrm{M}$ e ativada quimicamente por solução de $\mathrm{HCl}$ a $1,5 \mathrm{M}$. Ambas calcinadas antes da análise térmica.

De acordo com a Figura 2, a amostra de lama vermelha seca segundo a análise de TG, apresenta uma perda de massa de aproximadamente $1,79 \mathrm{mg}$ na faixa que compreende a temperatura de 40 a $800^{\circ} \mathrm{C}$, possivelmente associada à presença de umidade. A amostra apresentou um decréscimo ao longo de todo o ensaio, porém a partir de $680^{\circ} \mathrm{C}$ mostrou-se que a mesma estaria tornando-se estável. Também é possível notar uma perda de $0,6 \mathrm{mg}$, aproximadamente, entre $40^{\circ} \mathrm{C}$ a $250^{\circ} \mathrm{C}$. Nas 
temperaturas entre $250^{\circ} \mathrm{C}$ a $300^{\circ} \mathrm{C}$ ocorreu uma perda de massa de $0,4 \mathrm{mg}$. Entre 300 a $680^{\circ} \mathrm{C}$ a amostra obteve uma perda de $0,6 \mathrm{mg}$, tornando-se estável a $680^{\circ} \mathrm{C}$ em diante. No que diz respeito à DTA, o gráfico mostra, que ouve o aparecimento de picos endotérmicos nas temperaturas de $50^{\circ} \mathrm{C}, 287^{\circ} \mathrm{C}$ e $370^{\circ} \mathrm{C}$, sendo o que primeiro corresponde a provável perda de água da amostra, sendo o segundo o mais intenso. A partir de $600^{\circ} \mathrm{C}$ nota-se que ocorreu uma interferência durante o ensaio, pois o mesmo apresenta pequenas ranhuras no gráfico.

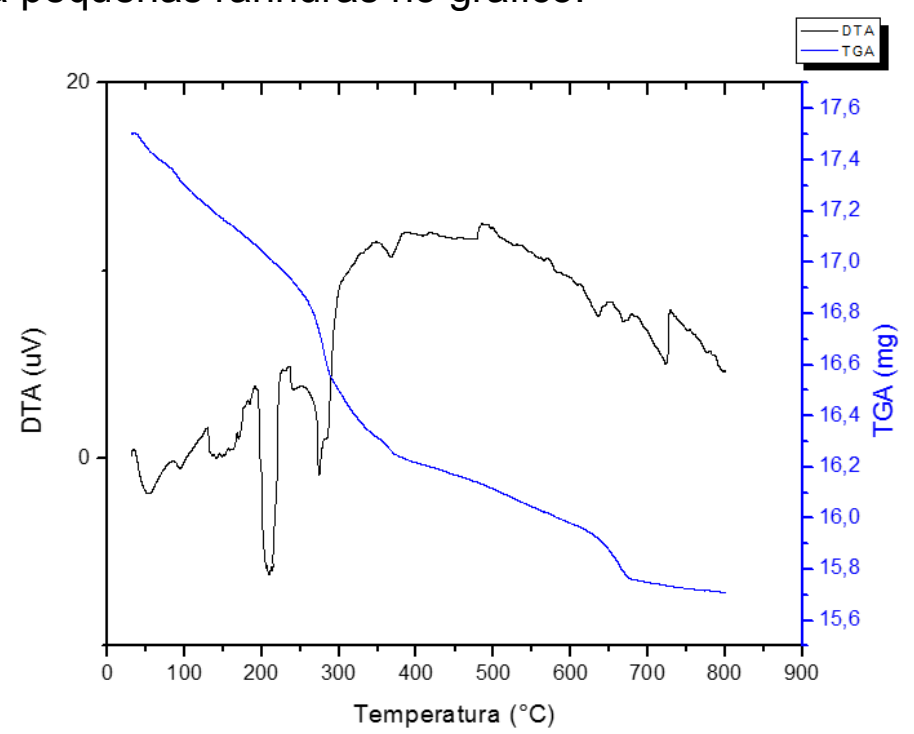

Figura 2. Análise térmica da lama vermelha seca sem tratamento.

$\mathrm{Na}$ Figura 3, ocorre o aparecimento de picos endotérmicos nas temperaturas de $65^{\circ} \mathrm{C}$, $325^{\circ} \mathrm{C}, 556^{\circ} \mathrm{C}, 691^{\circ} \mathrm{C}$ e $790^{\circ} \mathrm{C}$. Quanto a TG, a perda final de massa da amostra foi de $1,215 \mathrm{mg}$ correspondente $7,390 \%$. Nota-se que em torno de $700^{\circ} \mathrm{C}$ não há mais perda de massa, o que indica que o pequeno pico endotérmico é na verdade um sinal de interferência na análise.

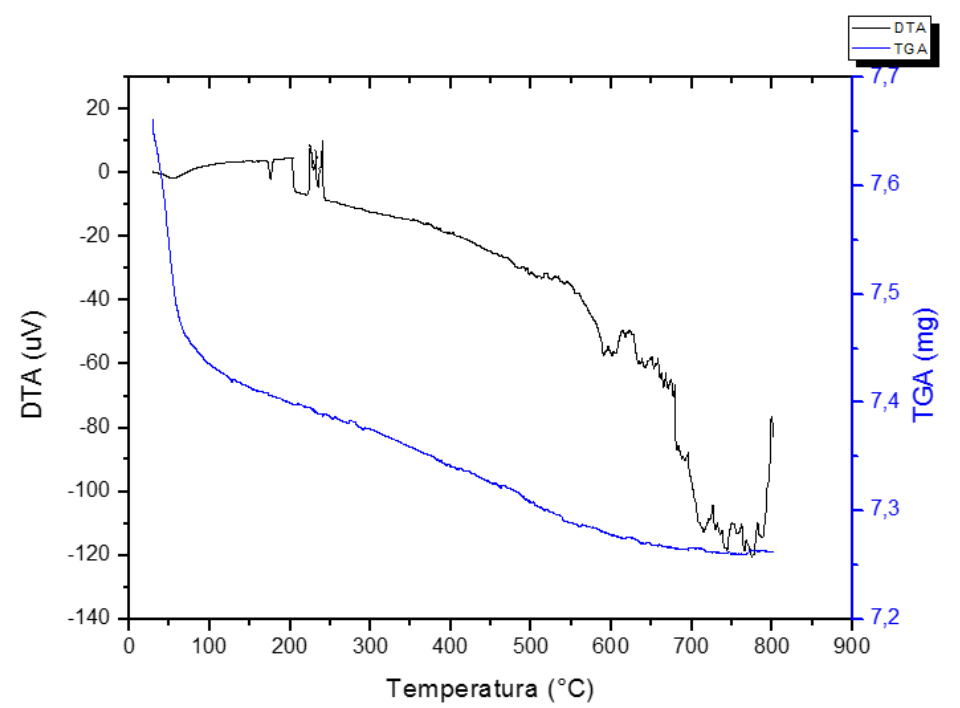

Figura 3. Análise térmica da LVAPH.

A Figura 4a mostra a perda de massa da amostra LVAAC, onde os principais picos endotérmicos da analise são $57^{\circ} \mathrm{C}, 176^{\circ} \mathrm{C}, 590^{\circ} \mathrm{C}$ e $744^{\circ} \mathrm{C}$, apresentando perda de massa de $4,939 \%$ no total. A Figura $4 \mathrm{~b}$ mostra a análise térmica da amostra LVAHP, e se distingue das outras amostras quando observa-se os picos endotérmicos bem definidos e facilmente identificáveis nos pontos 511 e $528^{\circ} \mathrm{C}$ com perda de massa final 
de $5,488 \%$ da massa total utilizada na análise. Já na Figura 4c, LVAAC2, há uma perda de massa de $0,812 \mathrm{~g}$, o que corresponde a $5,419 \%$, que é menos que a amostra da Figura 4b.
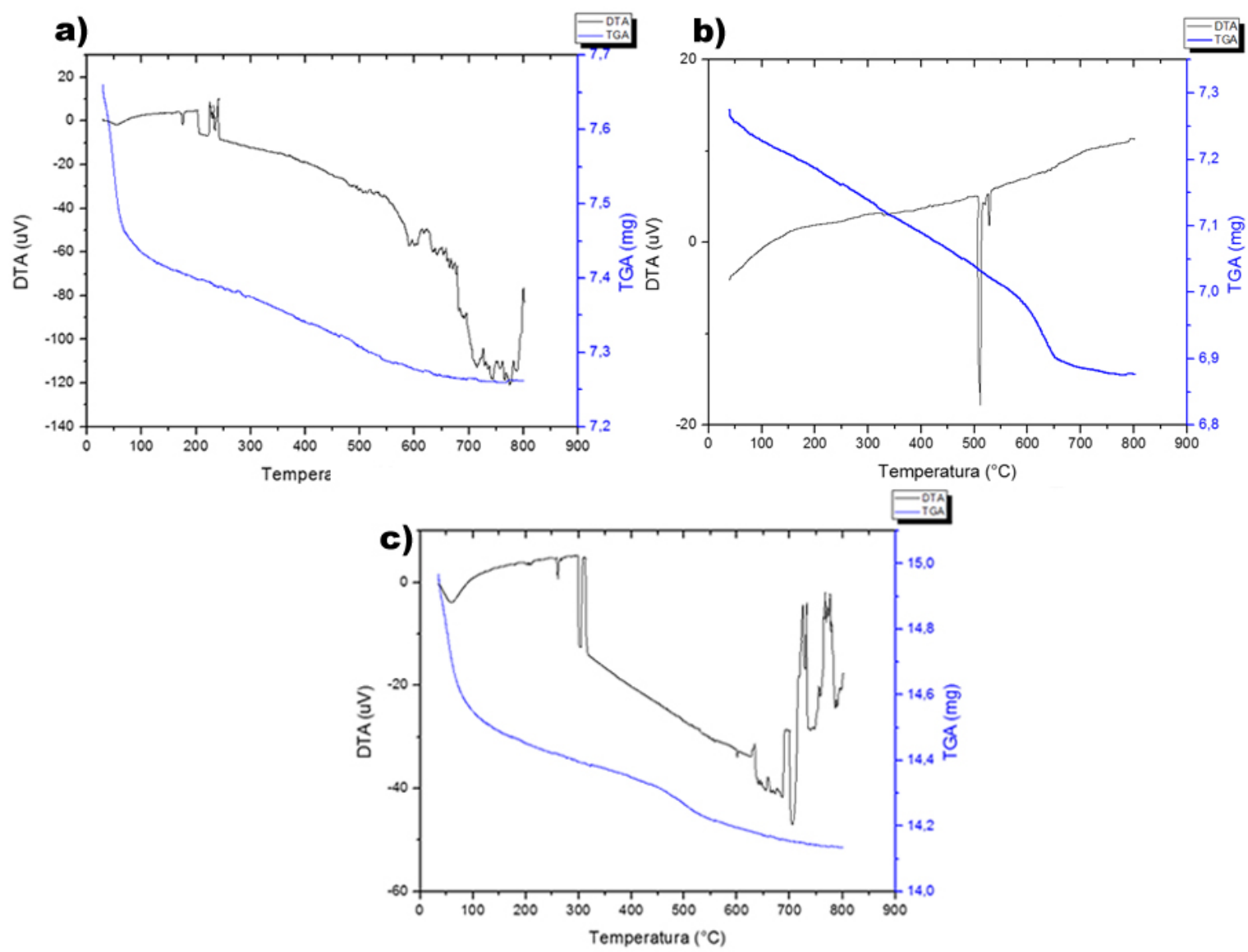

Figura 4. Análise térmica da LVAAC (a); da LVAHP (b); e da LVAAC2 (c).

Os termogramas mostram quatro fases de perda de massa. A primeira ocorreu no intervalo de $40^{\circ} \mathrm{C}$ a $176^{\circ} \mathrm{C}$, correspondente à evaporação de água adsorvida fisicamente. A segunda e a terceira ocorreram na faixa de $176-450^{\circ} \mathrm{C}$ e na faixa de $450-600^{\circ} \mathrm{C}$, respectivamente, que foram atribuídos à perda de água quimicamente adsorvida principalmente devido à decomposição da gibbsita e diáspora. Na faixa de $600-800^{\circ} \mathrm{C}$ há uma última perda de massa que corresponde à liberação de $\mathrm{CO}_{2}$ durante a calcinação da calcita que gera um último pico endotérmico a cerca de $805^{\circ} \mathrm{C}$ é resultado da decomposição da calcita [4].

A Figura 5 mostra as análises de Espectrômetro de Raios- $X$ das amostras estudadas e a Tabela 1 mostra o resultado obtido por Espectrômetro para todos os elementos, sendo que, segundo Souza [8], os valores correspondentes ao oxigênio deveriam ser excluídos, pois sua alta concentração poderia mascarar os resultados reais dos outros elementos, porém como a lama vermelha é constituída de uma mistura de óxidos, é possível considerar que os elementos químicos observados na análise compõem grupos oxigenados como $\mathrm{Al}_{2} \mathrm{O}_{3}, \mathrm{SiO}_{2}, \mathrm{CaO}$ e $\mathrm{Fe}_{2} \mathrm{O}_{3}$. 

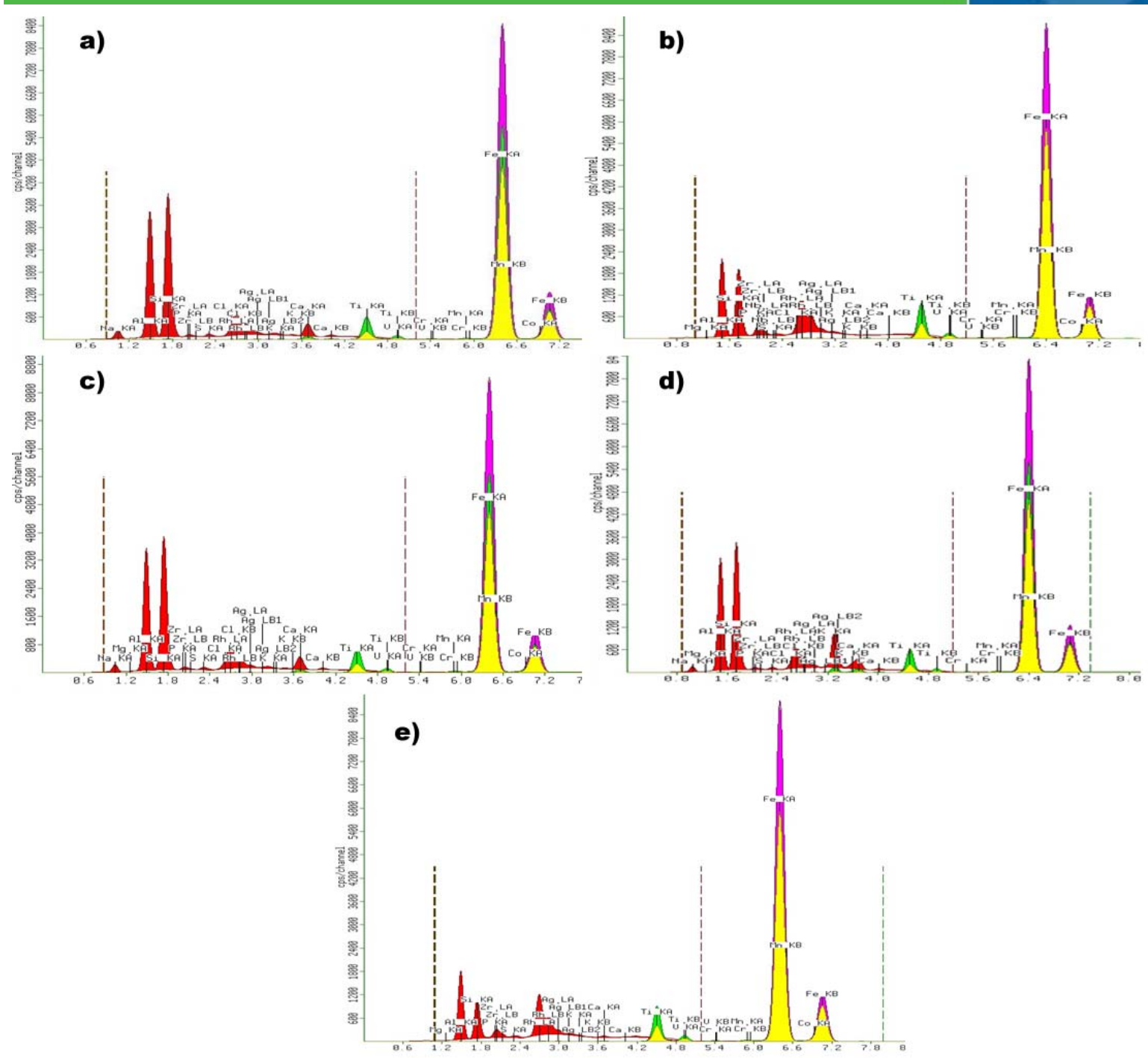

Figura 5. Análise de espectrômetro de raios-X da lama vermelha seca (a); da LVAAC (b); da LVAPH (c); da LVAHP (d); e da LVAAC2 (e).

$\mathrm{Na}$ Tabela 1, observa-se um aumento nas quantidades de alguns dos constituintes majoritários. Segundo Magalhães [9] esse aumento é devido ao tratamento térmico, que ocasionou a perda de água estrutural e em consequência de algumas reações de estado sólido que ocorrem na lama vermelha durante o tratamento térmico realizado. Manfroi [4], afirma que a presença de $\mathrm{Na}_{2} \mathrm{O}$ nas amostras deve-se a adição de hidróxido de sódio durante a etapa da digestão do processo Bayer. As amostras ativadas por solução de ácido clorídrico não possuem valores significativos devido à provável afinidade entre sódio e cloro. Tal afirmação ganha forças ao observarmos o percentual de cloro contido nas amostras tratadas com ácido clorídrico. 
Tabela 1. Componentes contidos nas cinco amostras de lama vermelha obtidos através do espectrômetro de raios-X

\begin{tabular}{cccccc}
\hline COMPONENTES & LV & LVAAC & LVAPH & LVAAC2 & LVAHP \\
\hline $\mathrm{Fe}_{2} \mathrm{O}_{3}$ & $45,556 \%$ & $73,616 \%$ & $46,651 \%$ & $78,129 \%$ & $48,294 \%$ \\
\hline $\mathrm{SiO}_{2}$ & $21,446 \%$ & $7,795 \%$ & $20,732 \% \%$ & $4,066 \%$ & $20,123 \%$ \\
\hline $\mathrm{Na}_{2} \mathrm{O}$ & $18,186 \%$ & $0 \%$ & $16,214 \%$ & $0 \%$ & $12,652 \%$ \\
\hline $\mathrm{TiO}_{2}$ & $6,591 \%$ & $12,861 \%$ & $7,777 \%$ & $12,311 \%$ & $7,360 \%$ \\
\hline $\mathrm{Al}_{2} \mathrm{O}_{3}$ & $3,124 \%$ & $1,502 \%$ & $3,110 \%$ & $1,197 \%$ & $2,921 \%$ \\
\hline $\mathrm{CaO}$ & $2,251 \%$ & $0,105 \%$ & $2,433 \%$ & $0,231 \%$ & $2,277 \%$ \\
\hline $\mathrm{ZrO}_{2}$ & $1,502 \%$ & $2,508 \%$ & $1,666 \%$ & $2,653 \%$ & $1,578 \%$ \\
\hline $\mathrm{Cl}$ & $0,252 \%$ & $0,109 \%$ & $0,230 \%$ & $0 \%$ & $0,225 \%$ \\
\hline $\mathrm{Ag}_{2} \mathrm{O}$ & $0,227 \%$ & $0,198 \%$ & $0,220 \%$ & $0,207 \%$ & $0,231 \%$ \\
\hline $\mathrm{SO}_{3}$ & $0,192 \%$ & $0,056 \%$ & $0,179 \%$ & $0,066 \%$ & $0,180 \%$ \\
\hline $\mathrm{MnO}_{\mathrm{Co}_{3} \mathrm{O}_{4}}$ & $0,152 \%$ & $0,341 \%$ & $0,203 \%$ & $0,310 \%$ & $0,167 \%$ \\
\hline $\mathrm{V}_{2} \mathrm{O}_{5}$ & $0,146 \%$ & $0,231 \%$ & $0,152 \%$ & $0,238 \%$ & $0 \%$ \\
\hline $\mathrm{K}_{2} \mathrm{O}$ & $0,093 \%$ & $0,233 \%$ & $0,150 \%$ & $0,234 \%$ & $0 \%$ \\
\hline $\mathrm{Cr}_{2} \mathrm{O}_{3}$ & $0,075 \%$ & $0,045 \%$ & $0,085 \%$ & $0,044 \%$ & $3,824 \%$ \\
\hline $\mathrm{P}_{2} \mathrm{O}_{5}$ & $0,061 \%$ & $0,154 \%$ & $0,078 \%$ & $0,125 \%$ & $0,092 \%$ \\
\hline $\mathrm{MgO}$ & $0 \%$ & $0,066 \%$ & $0,054 \%$ & $0,163 \%$ & $0,056 \%$ \\
\hline & & & & $0,026 \%$ & $0,020 \%$ \\
\hline
\end{tabular}

As alíquotas retiradas nas cinéticas de adsorção das amostras LV, LVAAC e LVAPH já filtradas, foram pesadas e tituladas com solução de $\mathrm{KOH} 0,1 \mathrm{M}$ para determinação da quantidade necessária para apresentarem a viragem de coloração de cada uma das mesmas. Com tais dados pôde-se determinar os índices de acidez das amostras de diesel leve resultante das cinéticas de adsorção, em seus respectivos intervalos de tempo. A Tabela 2 compara os índices de acidez obtidos nas três condições de adsorção: seca (LV), ativada por ácido clorídrico (LVAAC) e ativada por peróxido de hidrogênio (LVAPH).

Tabela 2. Índice de acidez das amostras de diesel leve adsorvidos por LV, LVAAC e LVAPH

\begin{tabular}{cccc}
\hline TEMPO DE & \multicolumn{3}{c}{ ÍNDICE DE ACIDEZ (IA) EM mg DE KOH/g } \\
\cline { 2 - 4 } ADSORÇÃO & LV & LVAAC & LVAPH \\
\hline 2 min & 54,27 & 55,63 & 55,64 \\
\hline 5 min & 57,24 & 61,72 & 62,94 \\
\hline 7 min & 58,30 & 55,02 & 56,44 \\
\hline $10 \mathrm{~min}$ & 66,08 & 56,75 & 57,62 \\
\hline $20 \mathrm{~min}$ & 52,13 & 56,46 & 60,37 \\
\hline $30 \mathrm{~min}$ & 57,38 & 56,31 & 59,19 \\
\hline $40 \mathrm{~min}$ & 57,16 & 55,81 & 70,54 \\
\hline $50 \mathrm{~min}$ & 56,18 & 57,50 & 59,80 \\
\hline $60 \mathrm{~min}$ & 56,18 & 55,91 & 51,33
\end{tabular}

$\mathrm{O}$ pH da lama após a modificação por ativação provavelmente se deslocou para valores menores que 4,0 e essa situação poderia promover alteração na composição química da lama afetando o processo de adsorção [8] Para Costa [10], os óxidos contidos na lama vermelha apresentam um caráter anfótero devido as cargas que dependem do $\mathrm{pH}$. No caso da LVAAC que foi ativada em meio ácido, a eliminação do $\mathrm{Na}_{2} \mathrm{O}$ de sua composição diminui sua basicidade elevando, consequentemente, sua acidez e modificando suas propriedades adsorventes.

Entre as possíveis causas do aumento da acidez nas cinéticas de adsorção estão o elevado teor de ácido clorídrico na solução de ativação química (37\%) e o equívoco 
cometido na lavagem da lama vermelha, onde não houve o controle do pH da água de lavagem e, devido a esse fato, é muito provável que a amostra LVAAC esteja exacerbadamente ácida.

Para a segunda metodologia de cinética de adsorção foram utilizadas as amostras de lama vermelha seca (LV2), ativada por solução de ácido clorídrico a 1,5 M (LVAAC2) e por solução de hidróxido de potássio a 1,5 M (LVAHP) e o biocombustível diesel leve desacidificado através da extração líquido-líquido. O teste do índice de acidez ocorreu seguindo os mesmos passos adotados na primeira metodologia de cinética de adsorção, adicionando a solução de $\mathrm{KOH}$.

Observa-se na Tabela 3, que no intervalo de tempo entre 30 e 50 minutos ocorrem as reduções mais bruscas de todos os outros intervalos. Sendo o índice de acidez da amostra LVAAC2 no tempo de 50 minutos o menor índice de acidez, mostrando que a ativação ácida possui eficácia comprovada quando é feito o controle do $\mathrm{pH}$ da água de lavagem da lama ativada por ácidos. Esse fato comprova a hipótese de a amostra LVAAC se encontrar bastante ácida, pois isso comprovaria sua ineficiência.

Tabela 3. Índice de acidez das amostras de diesel leve (após extração líquido-líquido) adsorvidos por LV2, LVAAC2 e LVAHP

\begin{tabular}{cccc}
\hline TEMPO DE & \multicolumn{3}{c}{ ÍNDICE DE ACIDEZ (IA) EM mg DE KOH/g } \\
\cline { 2 - 4 } ADSORÇÃO & LV2 & LVAAC2 & LVAHP \\
\hline 2 min & 9,7638 & 10,7061 & 9,6820 \\
\hline 5 min & 10,8511 & 9,7493 & 9,7154 \\
\hline 7 min & 9,6867 & 10,2935 & 9,6581 \\
\hline $10 \mathrm{~min}$ & 9,6959 & 9,6439 & 9,6392 \\
\hline $20 \mathrm{~min}$ & 9,4718 & 9,6250 & 9,5177 \\
\hline $30 \mathrm{~min}$ & 9,4037 & 9,3101 & 9,4855 \\
\hline $40 \mathrm{~min}$ & 9,3278 & 9,2400 & 9,5780 \\
\hline $50 \mathrm{~min}$ & 9,4993 & 9,1752 & 9,5733 \\
\hline $60 \mathrm{~min}$ & 9,5085 & 10,7368 & 9,7930
\end{tabular}

A técnica de tratamento com ácido é uma maneira de melhorar a adsorção da lama vermelha, por ser capaz de remover fósforo inorgânico e metais pesados [11]. A não linearidade dos índices de acidez, ou seja, o fato de no decorrer do tempo de adsorção haver algumas oscilações pode ser explicado pela diferença de agitação das amostras no agitador magnético, uma vez que as diferenças de condições interferem nos resultados.

É possível observar a partir da Tabela 3, que a lama vermelha tem uma capacidade de adsorção elevada, menor somente do que a do carvão ativado, o qual tem área superficial aproximadamente 10 vezes maior que a lama vermelha. Porém ao comparar-se a capacidade de adsorção com adsorventes do tipo argilominerais, como a argila montmorilonita, a capacidade de adsorção da lama vermelha apresenta-se superior [8].

\section{CONCLUSÃO}

A lama vermelha estudada apresentou uma boa capacidade de desacidificação, confirmando os estudos já realizados referentes à sua boa estrutura adsortiva na remoção de compostos orgânicos, mais precisamente os ácidos graxos livres. Todavia, sua eficiência é reduzida quando o índice de acidez do biocombustível for muito elevado tornando necessária uma extração líquido-líquido prévia. 
Concluiu-se de forma experimental que há possibilidades de utilização da lama para a remoção de hidrocarbonetos presentes no diesel leve, pois durante as cinéticas de adsorção, a lama vermelha se mostrou um bom adsorvente reduzindo $1,58822 \mathrm{mg}$ de $\mathrm{KOH} / \mathrm{g}$ do biocombustível. Através do estudo das cinéticas pode-se verificar que a reação atinge seu equilíbrio em um tempo superior a 60 minutos para os ácidos graxos livres presentes no diesel leve.

\section{REFERÊNCIAS}

1 Suares PAZ, Meneghetti SMP. $70^{\circ}$ aniversário do biodiesel em 2007: evolução histórica e situação atual no Brasil. Química Nova. 2007; 30: 2068-2071.

2 Gonçalves M, et al. Produção de carvão a partir de resíduo de erva-mate para a remoção de contaminantes orgânicos de meio aquoso. Ciência Agrotécnica. 2007; 31: 1386-1391.

3 Silva Filho EB, et al. Estudo sobre a utilização da lama vermelha para a remoção de corantes em efluentes têxteis. Química Nova. 2008; 31: 985-989.

4 Manfroi EP. Avaliação da Lama Vermelha como material Pozolânico em substituição ao cimento para produção de argamassas. Florianópolis: Universidade Federal de Santa Catarina; 2009.

5 Silva Filho EB, Alves MC, Da Motta M. Lama vermelha da indústria de beneficiamento de alumina: produção, características, disposição e aplicações alternativas. Revista Matéria. 2007; 12 (2): 322-338.

6 Mota SAP. Estudo do processo de Separação e Purificação da mistura Reacional da Transesterificação do óleo de palma (Elaeisguineensis, jacq) [dissertação de mestrado em engenharia química]. Belém: Universidade Federal do Pará; 2009.

7 Antunes MLP, Conceição FT, Navarro GRB. Caracterização da Lama Vermelha Brasileira (Resíduo do Refino da Bauxita) e Avaliação de suas Propriedades para Futuras Aplicações. São Paulo: Universidade Estadual Paulista; 2011.

8 Souza RS. Avaliação da Lama Vermelha na Remoção de Derivados de Petróleo Benzeno, Tolueno e Xileno (BTX) [tese de doutorado]. Campinas: Universidade Estadual de Campinas; 2013.

9 Magalhães EM. Estudo da extração de compostos de ferro da lama vermelha visando a extração e/ou recuperação de compostos de titânio [tese de doutorado]. Belém: Universidade Federal do Pará; 2012.

10 Costa ETS, et al. Caracterização de subproduto da indústria de alumínio e seu uso na retenção de cádmio e chumbo em sistemas monoelementares. Química Nova. 2009; 32 (4): 868-874.

11 Santona L, Castaldi $P$, Melis $P$. Evaluation of the interaction mechanisms between red mud and heavy metals. Journal of Hazardous Materials. 2006; 136: 324-329. 